\title{
Partners wanted to run research lab in space
}

\section{NASA seeks wider research-community involvement in the International Space Station.}

\section{BY ADAM MANN}

$\mathrm{F}$ ew births involve as much labour as that of the International Space Station (ISS). After 34 shuttle flights, 24 Soyuz missions, 43 visits by unmanned capsules, and well over US $\$ 100$ billion invested by the United States, Russia, Japan, Canada and Europe, the station is now nearing completion. The final bits of hardware, including the Alpha Magnetic Spectrometer, a long-delayed cosmic-ray experiment, will arrive as early as February 2011, on the last space-shuttle flight currently budgeted for. Now, decades after the station was first proposed and more than a dozen years after construction began, NASA must find a way to make its part of the effort by far the largest - worthwhile.

On 10 December, NASA will hold a public meeting in Washington DC to discuss the future of the US portion of the space station as a science facility. Congress declared the US share a national laboratory in 2005, thereby opening it up to public and private research. This year's NASA authorization bill, passed in September, requires the agency to establish an independent, non-profit entity to manage the lab. The upcoming meeting is meant to draw in prospective partners for the venture.

"The ISS is a completely unique asset," says Jeanne DiFrancesco, a principal at ProOrbis, a management consultancy based in Malvern, Pennsylvania, which was hired by NASA to create a 'reference model' for the administration of the lab. "Managed well, it could facilitate the development of new categories of research."

\section{GETTING IT TOGETHER}

For much of its long assembly phase, the ISS has been an active science facility. A 2009 NASA report lists more than 100 experiments on the station between 2000 and 2008, in technology development, physical and materials sciences, biological sciences, Earth observation and human research, including ways to counter the effects of 'low- $g$ ' on the body.

Today the United States' share of the ISS includes the Destiny pressurized lab as well as access to the Japanese-built Kibo and European-built Columbus modules. In addition to the microgravity environment, the ISS offers exposure to the vacuum of space, to radiation, atomic oxygen and extremes of temperature.

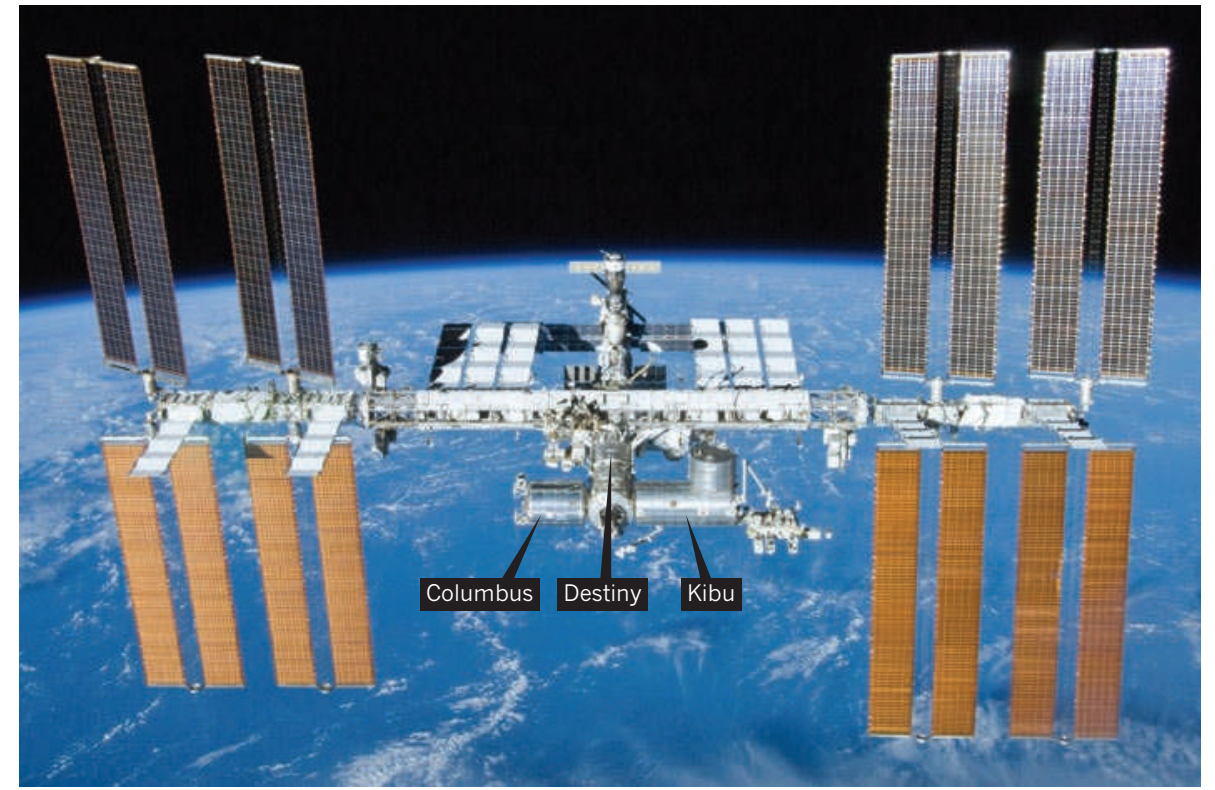

The International Space Station's three main laboratory modules seen from the space shuttle Atlantis.

The station's exterior is studded with sites for the attachment of instruments that can observe Earth or space. They provide anywhere from 100 to 300 possible experiment locations, says Mark Uhran, NASA's assistant associate administrator for the ISS.

But while interviewing researchers about the potential of the ISS, DiFrancesco says that she encountered some scepticism about whether the station could serve the scientific community in a meaningful way. To counter such criticism, she says, any new organization that manages science on the station must begin with a concentrated outreach campaign that demonstrates a clear commitment to the research community's needs, interests and concerns. According to the reference model, it would smooth the road for scientists and also foster an impartial approach to choosing what science ends up in space. The idea of creating such an organization was floated in the 2009 Augustine report, a critical review of the US human space-flight programme commissioned by President Barack

\section{DNATURE.COM}

For more on the high cost of science in space see: go.nature.com/zjanow Obama. The ProOrbis reference model, which was publicly presented on 16 November at a meeting of the American Astronautical Society in Cape Canaveral, Florida, reaches the same conclusion: an independent entity is needed to act as a buffer between NASA's operations managers and the broader community that could put the ISS to use.

Its role might resemble that of the Space Telescope Science Institute in Baltimore, Mary-land, which helps to oversee research on Hubble and other space telescopes. Among its responsibilities would be building an awareness of the research possibilities on the station, matching prospective projects with funding and helping primary investigators to navigate the space agency's bureaucracy, says DiFrancesco. But unlike the basic research done on the Hubble telescope, ISS projects could come from many sectors, including other government agencies, public universities, pharmaceutical companies, private labs and chemical and materials manufacturing firms, she adds.

"The ultimate hope is that something new will be discovered in the microgravity environment aboard the ISS that can lead to useful insights on the ground," says Uhran.

In theory, such a possibility has been open to US researchers for years, but a completed ISS with a six-person crew can support longerterm studies that require more care and attention than would have been practical in the past. 
This increased scope is "amazing" says Jeanne Becker, chief science officer at the biotechnology company Astrogenetix in Austin, Texas, and a faculty member at Baylor College of Medicine in Houston. Becker has already cultivated tumour cells in rotating bioreactors aboard the ISS to investigate changes in the cells' growth and functioning.

If set up properly, management of research on the ISS by a private non-profit entity could make the process of selecting experiments more transparently based on genuine applicability to life on Earth, says Jeff Jonas, senior vice-president of research and development at Shire Pharmaceuticals in Philadelphia, Pennsylvania. "It would open up the station to the marketplace of ideas," he says, adding that having more researchers and companies involved could create competition for better experiments.

\section{BAD VIBES}

NASA has started making moves in this direction. Earlier this year, the agency opened the ISS to biological research funded by the National Institutes of Health, which awarded the first round of grants in September. With an independent body overseeing research, the ISS could also host experiments from other agencies, such as the US Forest Service, the National Oceanic and Atmospheric Administration and the US Geological Survey, says Erika Wagner, an aerospace biomedical engineer and executive director of the X Prize Lab at the Massachusetts Institute of Technology in Cambridge.

Yet plenty of challenges remain that could prejudice the success of the ISS as a national laboratory. Among these are concerns over the quality of the research environment aboard

\section{Every month that the station is not being fully used by researchers, it loses value.} the ISS. For example, vibrations on the station (known as $g$-jitter) caused by machinery and human movement can affect some experiments. NASA has installed a special rack for the most sensitive experiments that actively counteracts vibrations, and provided damping material for other research, says Uhran.

A more fundamental obstacle is the question of how to access the ISS in a cost-effective way. In November 2009, the US Government Accountability Office released a report identifying the high cost of launching a payload as one of the biggest challenges the lab faces. Although the nascent commercial space-flight industry is expected eventually to make the ISS more accessible, it will be years before commercial transport can fully meet researchers' needs (see 'Station to rely on private space flight').

Yet, as DiFrancesco's model points out, every month that the station is not being fully used by researchers, it loses value. Once a non-profit organization is established, NASA expects to begin research and development, but it will take a few years before the enterprise is running at full throttle, says Uhran. In the meantime, the agency and its international partners are continuing research into human exploration in space. In October, the European Space Agency (ESA) issued a call for proposals in technology and biomedical research that would help to prepare for the next steps of human exploration beyond low-Earth orbit, says Martin Zell, ESA's head of research operations in human space flight, microgravity and exploration.

Ultimately, to take advantage of what the ISS offers, it will be crucial to get the science management right, says Alan Stern, a planetary scientist at the Southwest Research Institute in San Antonio, Texas, and NASA's former associate administrator for science. "Like a baby, the ISS has lots of potential," he says. "NASA is working to turn that potential into a great outcome for the ISS." — SEE EDITORIAL P.599

\section{AFTER THE SHUTTLE}

\section{Station to rely on private space flight}

As it works to turn the International Space Station (ISS) into a national laboratory, NASA will have to deal with a major bottleneck: transporting crew and equipment to the facility and back. The existing fleet of space shuttles, each with a carrying capacity of 22,700 kilograms per launch, is set to retire next year, leaving the agency to rely on the unmanned Russian Progress spacecraft, which has a cargo capacity of only $1,700 \mathrm{~kg}$, and the Soyuz spacecraft to transport crew members. To fill the gap, NASA hopes to rely on private space flight.

"The developing commercial industry can open the floodgates for NASA to do more research and get more people up to the ISS," says John Gedmark, executive director of the Commercial Spaceflight Federation in Washington DC, a space-flight industry group.

NASA currently has contracts with two companies - Orbital Sciences Corporation in Dulles,

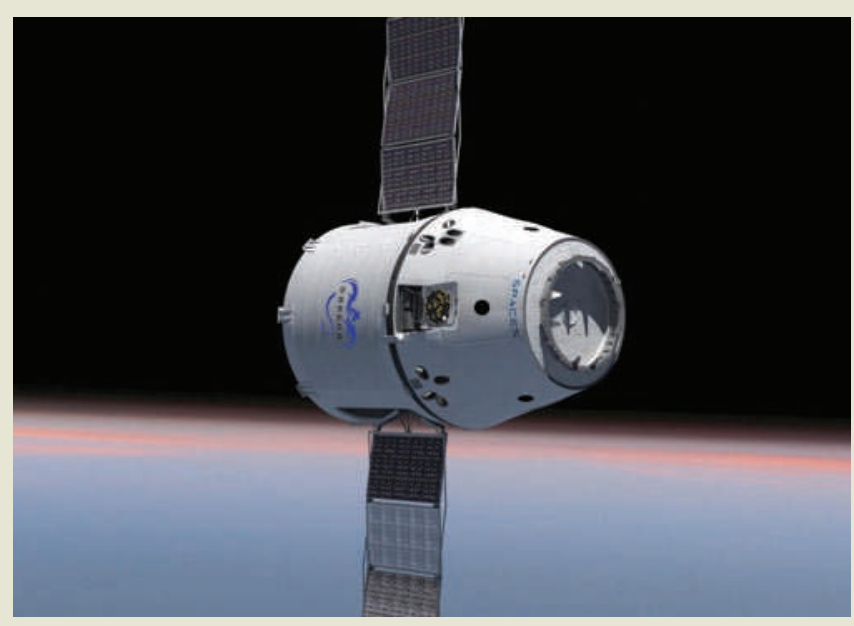

Virginia, and Space Exploration Technologies Corporation (SpaceX) in Hawthorne, California - to transport supplies to the ISS once the shuttle stops flying. As well as providing capacity, multiple providers can drive down costs through competition, allowing more experiments to be done, says Gedmark.

Commercial companies are nearly ready to accept the hand-over from NASA. SpaceX hopes to make the first launch of its reusable Dragon spacecraft (pictured), which can carry $6,000 \mathrm{~kg}$, into orbit on 7 December. The company has two further flights scheduled for next year, the second of which will dock with the ISS and deliver cargo.

But during an address at the
Marshall Space Flight Center in Huntsville, Alabama, on 16 November, NASA administrator Charles Bolden spoke about the risks in this strategy. "If there's any delay in delivery of commercial capability to take cargo to the station, we could find ourselves in a situation as bad as having to de-man the station or take it down to three people," he said. Minor delays with Orbital's Cygnus spacecraft, which will carry supplies and research experiments to the station, have already postponed a demonstration flight from late 2010 to spring 2011.

Bolden advocates an additional shuttle flight to preserve access to the ISS until private space companies are ready to take over, a move currently mandated in the 2010 NASA authorization bill. But the US $\$ 500$-million launch remains unfunded and could be on the chopping block as Congress seeks to reduce spending. A.M. 